\title{
NEUROCRIPTOCOCOSE POR CRYPTOCOCCUS NEOFORMANS NÃO CAPSULADO
}

\author{
C.S. LACAZ *, ELISABETH M. HEINS-VACCARI **, NATALINA T. MELO **, \\ O.A. MORENO-CARVALHO ***, M.L.S. SAMPAIO ****, L.S. NOGUEIRA ****, \\ R.J.S. BADARó $* * * *$, J.A. LIVRAMENTO $* * * * *$
}

RESUMO - Os autores registram um caso de neurocriptococose em paciente HIV-negativo, por Cryptococcus neoformans acapsulado ou deficiente em cápsula. o quadro neurológico era de meningoencefalite subaguda, compiativel ao diagnóstico de neurotuberculose, pelo exame do liquido cefalorraqueano (LCR), Estruturas leveduriformes foram encontradas no interior de macrófagos, ao exame citomorfológico do LCR. Cultivo do sedimento do LCR revelou a presença de Cryptococeus neoformans não capsulado (identificação bioquímica). A inoculiaçåo da amostra em camundongo, por via intraperitoneal, permitiu a produção de cápsula que desaparecia em cultivos. Foi estudada a micromorfologia do fungo à microscopia eletrônica de varredura. A evolução foi favorável com o emprego da anfotericina $B$ associada a 5-fluorocitosina. Năo foi caracterizada a variadade de Criptococeus neoformans agente do processo.

PALAVRAS-CHAVE: meningoencefalite, criptococose, Cryptococcus neoformans não capsulado, liquido cefalorraqueano.

Meningoencephalitis due to nonencapsulated Cryptococcus neoformans: ease report.

SUMMARY - The case of a patient with meningoencephafalitis due to a nonencapsuiated strain of Cryptococus neoformans is reported; he had no risk factors for the disease or AIDS. Clinical examination showed a chronic meningoencepahlitis first diagnosed as tuberculosis. In the second cerebrospinal fluid (CSF) examination after a week from admission yeasts appeared inside macrophage cells. CSF culture in Sabouraud medium disclosed nonencapsulated Cryptococcus neoformans (biochemical identification). Sample inoculation in mouse (intraperitoneal) evidenced a capsule that disappeared in several consecutive cultures. The morphology of the yeast was studied by electronic microscopy. After treatment with amphotericin B and 5-fluorocytosine the patient had a favorable evoluion. The significance of capsular material is discussed.

KEY WORDS: meningoencephalitis, cryptococeosis, nonencapsulated Cryptococeus neoformans, cerebrospinal fluid.

A literatura médica registra alguns casos de criptococose pela variante näo capsulada do Cryptococcus neoformans, sem especificação da variedade. KwonChung \& Bennett (1992)8 assinalam, a respeito da cápsula do C. neoformans, ser a mesma fator relevante de virulência desta levedura. Mutantes acapsuladas, aparecidas espontaneamente ou obtidas pela ação de substâncias mutagênicas, demonstram geralmente não possuir virulência, para animais de laboratório, sendo mais facilmente fagocitadas pelos leucócitos. Alguns pesquisadores associaram a variante acapsular com a infecção pelo vírus da AIDS. Este fato não é, todavia, verdadeiro. Acreditamos que as chamadas mutantes acapsuladas do $\mathbf{C}$. neoformans seriam melhor definidas como "deficientes em material capsular", como registram Farmer \& Komorowski (1973)4. No caso em apreço, tratava-se de uma

Laboratório de Micologia Médica do Instituto de Medicina Tropicai de Så Paulo e Laboratório de Investigação Médica (LIM) 53 da Faculdade de Medicina da Universidade de săo Paulo (FMUSP): * Professor Emérito e Chefe do Laboratório; ** Assistente. Serviço de Liquido Cefalorraqueano da Fundação José Silveira, Salvador: *** Médico Responsável. Servị̧o de Infectologia do Hospital Espanhol, Salvador: **** Médico Assistente. Centro de Investigações em Neurologia, LIM 15, FMUSP: ****** Médico Assistente. Aceite: 1-dezembro-1992.

Dr.Carlos da Silva Lacaz - Faculdade de Medicina da Universidade de Săo Paulo - Av. Dr. Arnaldo 455 - 01246-903 São Paulo SP - Brasil. 
lesão pulmonar com a presença de fungos semelhantes ao Blastomyces dermatitidis. A inoculação em camundongos por via intraperitoneal e cerebral permitiu o desenvolvimento da cápsula do C. neoformans.

Em nosso meio Capone et al. (1986)2, Severo et al. (1981)12 e Moreno Castillo et al. (1986)10 registraram casos de criptococose por amostras não capsuladas de C. neoformans. No caso registrado por Moreno Castillo et al.10 a lesão criptococócisa era cutânea, na região retro-auricular esquerda, havendo cura espontânea. Severo et al.12 observaram provável caso de criptococose pulmonar, com nódulos subpleurais onde foi verificada reação granulomatosa, com presença de numerosos elementos semelhantes a C. neoformans não capsulado. Capone et al.2 assinalaram, também, caso de criptococose pulmonar por Gryptococcus neoformans não capsulado, em paciente diabético.

Através de processo de radiação com raios ultravioleta, Bulmer et al. (1967)1 obtiveram mutantes não capsuladas de $\mathbf{C}$. neoformans. Outros trabalhos, como os de Fromtling et al. (1982)5, Harding et al. (1979)6, Kozel (1977)7, Levinson et al. (1971) 9 e Bulmer et al. (1967)1, referem dados de ordem micológica sobre as mutantes acapsuladas do C. neoformans. Em um caso de peritonite criptococócica por Cryptococcus neoformans var. neoformans (paciente em diálise), regis. trado por Morris et al. (1992)11, o exame bacterioscópico do líquido peritoneal revelou células leveduriformes com brotamento, sem cápsula evidente, sendo cultivado, todavia, C. neoformans var. neoformans.

\section{RELATO DO CASO}

USS, paciente branco, do sexo masculino, com 70 anos de idade, lavrador aposentado, natural e procedente de Campo Formoso, BA, observado na Fundação José Silveira, Salvador, BA. Admitido no dia 21.07.90 com queixa de cefaléia frontal, febre de caráter vespertino e perda de peso acentuada $(10 \mathrm{Kg}$ ) há cerca de 2 meses. Tinha passado de tuberculose osteo-articular tratada, hó aproximadamente 10 anos. Vinha transferido de outro hospital, onde dera entrada no dia 09.07.90 com quadro de cefaléia, desorientação e febre. Foi colhido líquido cefalorraqueano (LCR) no dia $10.07 .90 \mathrm{com}$ suspeita de meningite tuberculosa e introdução de esquema triplice, com melhora acentuada do quadro neurológico e desaparecimento da febre. No dia 17.07.90 realizou-se novo estudo do LCR que mostrou estruturas leveduriformes Gram positivas ao exame, inicialmente identificadas como Candida sp. Foi, então, transferido para esta Unidade para tratamento específico. Ao exame apresentava-se em bom estado geral, com niveis flutuantes de orientação, hidratado, corado, com dados vitais mantidos e exame segmentar sem alterações, com exceção de rigidez articular no joelho esquerdo e atrofia do membro inferior esquerdo. Introduzido esquema antifúngico com anfotericina $B$, na dose inicial de $5 \mathrm{mg} / \mathrm{dia}$, aumentando-se progressivamente até $30 \mathrm{mg} / \mathrm{dia}$, associada a 5 -fluorocitosina (4 g/dia). O esquema triplice foi suspenso.

A amostra de cultura do LCR foi encaninhada para identificação da espécie do fungo. sendo isolado Cryptococeus neoformans não capsulado, justificando o exame direto (tinta da China) negativo. Procedeu-se à avaliação para possiveis causas de depressão imunológica associada. Foi demonstrada linfocitopenia em diversos leucogramas e anergia cutânea. Não foi diagnosticada neoplasia ou síndrome da imunodeficiência adquirida. $O$ paciente evoluíu mantendo bom estado geral com melhora dos períodos de desorientação, afebril. Houve aumento dos niveis de creatinina, sendo suspensas as drogas por 2 dias e reintroduzidas sem intercorrências, com melhora progressiva.

\section{DIAgnóstico Micologico}

De Salvador, Bahia, recebemos cultivo leveduriforme isolado de LCR. O cultivo em lâmina, em ágar-fubá, revelou células globosas, sem filamentação. Prova de urease positiva e crescimento a 37 oC. Provas de assimilação - (a) positivas: dextrose, inositol, xilose, rafinose, galactose, sacarose, maltose; (b) positivas fracas: celobiose e trealose: (c) negativas: lactose, melibiose e $\mathrm{KNO}_{3}$.

Clamundongos inoculados com suspensão da levedura, por via intraperitoneal, morreram ao redor do $12^{\circ}$ dia de inoculação. A autópsia, o exame direto com tinta da China permitiu observar presença de leveduras com cápsula. No entanto, semeando órgãos (baço, figado, rim e cérebro) desses animais, o exame direto da cultura obtida demonstrou a presença de leveduras não capsuladas. A época não realiź́vamos a quimiotipagem de amostras de C. neoformans.

Microscopia eletrônica de varredura: células globosas a ovóides, com blastoconídios, ausência de cápsula (Fig. 1). 


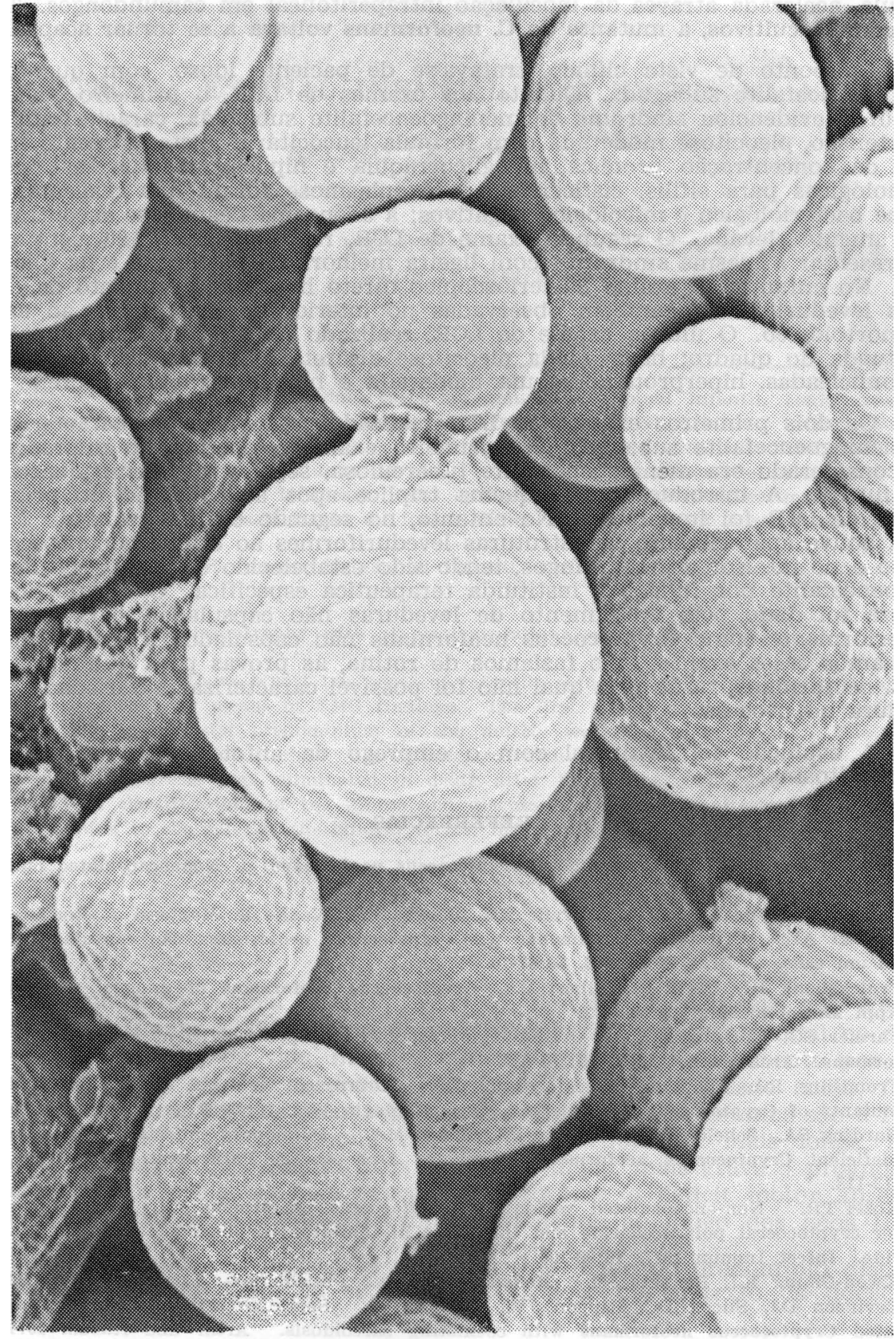

Fig. 1. Microscopia eletrônica de varredura mostrando blastoconídios globosos, destituído de cápsula, de Cryptococcus neoformans, notando-se um com brotamento no centro da fotografia. Aumento: 20400×.

\section{COMENTARIOS}

O caso apresentado, do ponto de vista micológico, é raro, estando bem documentada a amostra isolada através das provas bioquímicas e, principalmente, da microscopia eletrónica de varredura. Digno de registro foi a produção de 
cápsula, acelerada através da inoculação intraperitoneal em camundongos. Todavia, com os cultivos, a mutante do C. neoformans voltava a se tornar acapsulada.

Do ponto de vista clínico, tratava-se de paciente idoso, com quadro de meningoencefalite subaguda. Quanto aos exames de LCR, o primeiro realizado a 10-07-90 evidenciou síndrome de meningoencefalite subaguda, caracterizada por hipertensão, pleocitose moderada com fórmula leucocitária mista, aumento moderado da concentração proteica, hipoglicorraquia e hipoclororraquia; as reações imunológicas para sífilís, cisticercose e toxoplasmose foram não reagentes e o exame bacteriológico e micológico negativos; a adenosina deaminase encontrava-se ligeiramente elevada. O segundo exame de LCR, realizado a 17-07-90, continuava a apresentar a mesma síndrome, com ligeira melhora da pleocitose e da glicorraquia. No entanto, ao exame bacterioscópico direto houve aparecimento de estruturas leveduriformes, também observadas no interior de macrófagos ao exame citomorfológico. O último exame de LCR, realizado a 12-09-90, mostrou melhora acentuada do quadro: havia ainda pleocitose discreta às custas de células linfomononucleadas, hiperproteinorraquia moderada e hipoglicorraquia discreta.

Os dois primeiros exames de LCR realizados apresentavam características de meningoencefalite subaguda. Ao primeiro exame o diagnóstico diferencial a ser considerado era meningoencefalite tuberculosa, seguida de meningoencefalite por fungos. A introdução do esquema tríplice após a realização do primeiro exame de LCR foi imperativa. No entanto, no segundo exame, realizado 7 dias após, houve aparecimento de estruturas leveduriformes ao exame bacterioscópico direto e no interior de macrófagos, tendo sido estabelecido o diagnóstico de meningoencefalite por fungos $e$ instituída terapêutica específica. $O$ diagnóstico de certeza foi dado pelo crescimento de leveduras não capsuladas, caracterizadas posteriormente como Cryptococcus neoformans não capsulado. A época em que realizamos esses exames, não fazíamos de rotina, as provas para quimiotipagem do C. neoformans, razāo pela qual não foi possível caracterizar a variedade desta levedura no processo.

A evolução foi favorável com o emprego da anfotericina B associada à 5-fluorocitosina.

\section{REFERENCIAS}

1. Bulmer GS, Sans MD, Gunn CM. Cryptococeus neoformans: I. Nonencapsulated mutants. J Bacteriol 1967, 94:1475-1479.

2. Capone D, Gonçalves AJR, Andrade EM, Peyneau A, Wanke B, Montessi J, Romão PAA, Kritski AL. Criptococose pulmonar por Cryptococeus neoformans năo capsulado: relato de um caso. J Bras Med 1986, 50:67-70.

3. Cruickshank JG, Cavill R, Jelbert $M$. Cryptocoecus neoformans of unusual morphology. Appl Microbiol 1973, 25:309-312.

4. Farmer SG, Komorowski RA. Histologic response to capsule-deficient Cryptococcus neoformans. Arch Pathol 1973, 96:383-387.

5. Fromtling RA, Shadomy HJ, Jacobson Es. Decreased virulence in stable, acapsular mutants of Cryptococous neoformans. Mycopathologia 1982, 79:23-29.

6. Harding SA, Scheld WM, Feldman PS, Sande MA. Pulmonary infection with capsule-deficient Cryptococeus neoformans. Virchows Arch Abt A Path Anat Histol 1979, 382: 113-118.

7. Kozel TR. Non-encapsulated variant of Cryptococcus neoformans: II. Surface receptors for cryptococcal polysaccharide and their role in inhibiton of phagocytosis by polysacchiaride. Infect Immun 1977, 16:99-106.

8. Kwon-Chung KJ, Bennett JE. Medical mycology. Philadelphia: Lea \& Febiger, 1992.

9. Levinson DJ, Silcox DC, Rippon JW, Thomsen S. Septic arthritis due to nonencapsulated Cryptococcus neoformans with coexisting sarcoidosis. Arthr and Rheum 1974, 17: 1037-1047.

10. Moreno Castillo JL, Del Negro G, Heins-Vaccari EM, Melo NT. Primary cutaneous cryptococcosis. Mycopathologia 1986, 96:25-28.

11. Morris B, Chan YF, Reldy J, Woodgyer A. Cryptococcal peritonitis in a CAPD patient. J Med Vet Mycol 1992, 30:309-315.

12. Severo LC, Londero AT, Marting SC, Reolon M, Geyer RG. Provável criptococose pulmonar causada por Cryptococens neoformans não-capsulado. Rev Inst Med Trop Săo Paulo, 1981, 23:283-286. 